\title{
Shape and growth in European Atlantic Patella limpets (Gastropoda, Mollusca). Ecological implications for survival
}

\author{
João Paulo Cabral
}

Cabral, J. 2007. Shape and growth in European Atlantic Patella limpets (Gastropoda, Mollusca). Ecological implications for survival. - Web Ecol. 7: 11-21.

\begin{abstract}
Specimens of Patella intermedia, Patella rustica, Patella ulyssiponensis, and Patella vulgata were analyzed for shell and radula characteristics. Shell growth in P. rustica and P. ulyssiponensis was basically isometric, indicating that shell shape was constant during growth. On the contrary, shell growth in $P$. intermedia and $P$. vulgata was positively allometric, indicating that as shells increased in size, the base became more circular and the cone more centred and relatively higher. Radula relative size increased in the order $P$. ulyssiponensis, P. vulgata, P. intermedia and P. rustica, and had negative allometric growth in all species, indicating that radula grew less as shell increased in size. Data reported in the literature estimated that the lowest risk of dislodgment for a limpet is associated with a centred apex, and a (shell height)/(shell length) or (shell height)/(shell width) ratio of ca 0.53 . However, as reported for other limpets, in all four studied Patella species, shells were more eccentric and flat than this theoretical optimum. Data reported in the literature indicated that, in limpets, decreasing the (shell base perimeter)/(shell volume) or (shell surface area)/(shell volume) ratios by increasing size results in lower soft body temperature and desiccation. In the present study, P. rustica shells displayed the lowest ratios, and $P$. ulyssiponensis shells, the highest. Considering that the former species lives at high shore levels, and the latter species at low levels, it appeared that shell shape in European Atlantic limpets can be directly related to resistance to desiccation and high temperature stresses. Radula relative size (in relation to shell height) also increased with increasing level in the shore, suggesting that this might be due to a decreasing abundance of algae with increasing shore level.
\end{abstract}

J. Paulo Cabral (jpcabral@fc.up.pt), Center of Marine and Environmental Research (CIIMAR) and Faculty of Sciences, Univ. of Oporto, Rua do Campo Alegre, 1191, PL-4150181 Porto, Portugal.

Limpets are one of the most abundant molluscs in rocky shores. However, the rocky shore is a harsh environment, considering the huge force and impact of waves against the rocks. Additionally, at each tidal cycle, limpets are out of water for considerable period of time, being therefore exposed to high temperature and desiccation stresses.

Each limpet has its permanent place to live attached to the substratum in a slight depression in the rocks (home)
(Hyman 1967, Fretter and Graham 1994). After an excursion for feeding on algae, the animal commonly returns to its home. Foraging can occur at low tide, when the animal is emerged, or at high tide, during submersion, and can vary with the period of the day (Williams et al. 1999). Limpets are strongly adherent to the substratum, even while moving. Adhesion to the substratum during inactivity is accomplished by the secretion of a pedal mucus, with 
glue-like properties (Smith et al. 1999). While moving, limpets remain adhered due to suction (Ellem et al. 2002). Limpets "clump" or "hunker down" when disturbed. Shell clumping brings the lower rim of the shell into direct contact with the substratum; this creates friction between the shell and substratum that provides increased resistance to horizontal shear and prevents dislodgement (Ellem et al. 2002). Strong adhesion to the substratum reduces water loss, since there is a close fit between the shell and the substratum.

The four Patella species found in European Atlantic seawaters occupy different positions in the shore (Evans 1957, Fischer-Piette and Gaillard 1959, Ibañez 1982, Guerra and Gaudencio 1986). P. ulyssiponensis is a lowshore species, being out of water only at low tide. P. intermedia and P. vulgata occur at most levels, and can be ex- posed to air for considerable periods of time each tidal cycle. P. rustica Linné 1758 is restricted to high shore levels, being submerged at high tide, or only humidified by water splashes. Since the exact position of the animal in the shore directly influences the time to air exposure, these Patella species can exhibit different adaptations to the rocky shore environment.

This work was aimed to study shell shape and radula size in P. intermedia, P. rustica, P. ulyssiponensis and $P$. vulga$t a$, and to correlate these parameters with their habitat. In particular the following questions were raised: Have these species different shell shape and radula size?, Do shell shape and radula size change with growth?, and Can the morphological characteristics of each species be related to its survival under the dominant ecological conditions?

\section{Patella intermedia}

Patella rustica

Patella ulyssiponensis
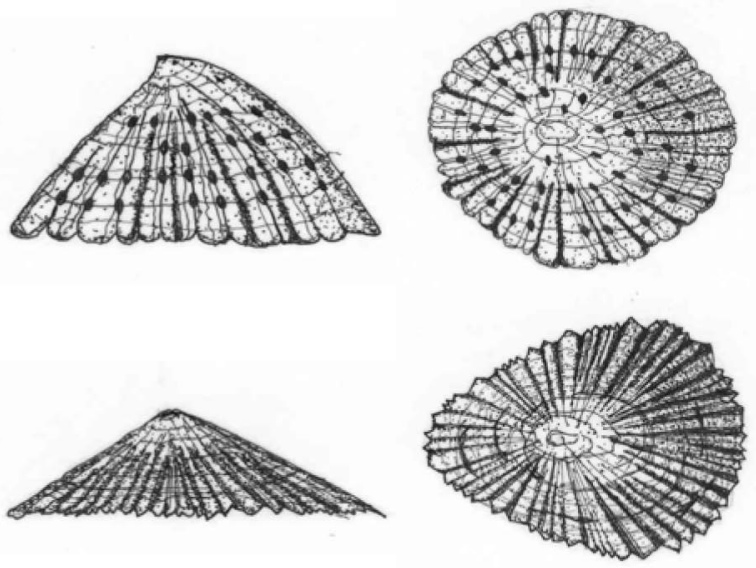

Patella vulgata

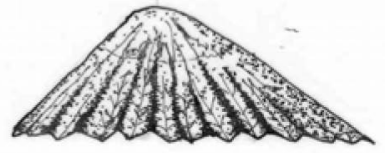

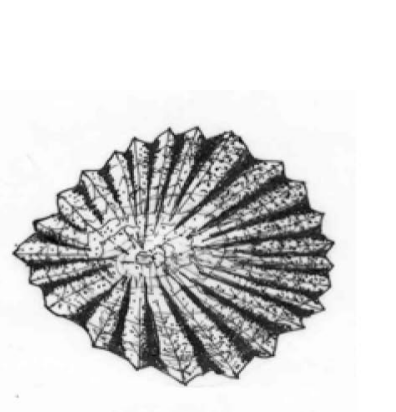
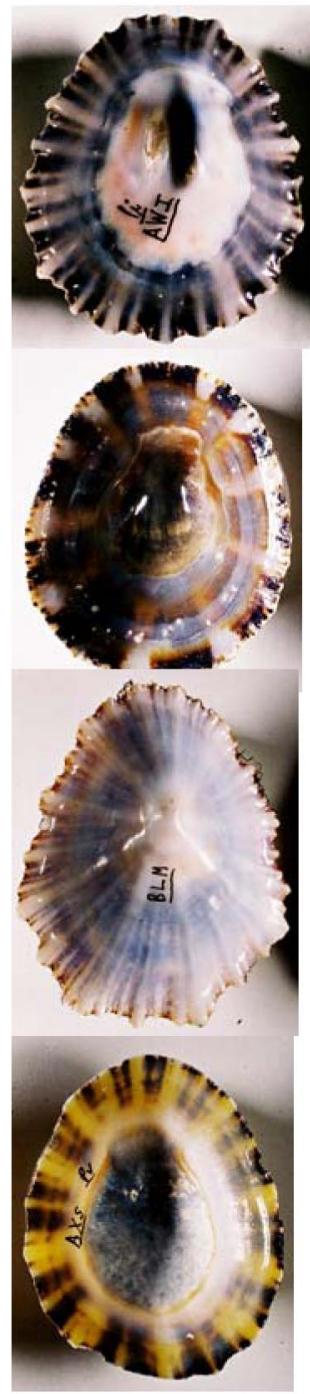

Fig. 1. Lateral (left), top (central) and interior (right) views of P. intermedia, P. rustica, P. ulyssiponensis and P. vulgata shells. 


\section{Materials and methods}

\section{The specimens}

Specimens were collected at the following rocky shores along the Portuguese continental coast (coordinates, $\left.{ }^{\circ} \mathrm{W},{ }^{\circ} \mathrm{N}\right)$ : Afife (-8.8754, 41.7798), Aguçadoura (-8.7821, 41.4319), Amoreira (-8.8434, 37.3553), Baleal (-9.3382, 39.3742), Carcavelos (-9.3249, 38.6747), Foz do Arelho (-9.2253, 39.4383), Luz (-8.7250, 37.0879), Marinha (-8.4109, 37.0912), Monte Estoril (-9.3991, 38.7039), São João do Estoril (-9.3662, 38.6936), and Telheiro (-8.9781, 37.0478). P. intermedia and $P$. vulgata were collected at mid-shore, $P$. rustica at high-shore, and $P$. ulyssiponensis at low-shore levels. The total number of collected specimens were 726 for $P$. intermedia, 113 for $P$. rustica, 413 for $P$. ulyssiponensis, and 381 for P. vulgata. In the laboratory, the specimens were immersed for a few minutes in boiling water to separate the shell from the soft part. The radula was removed from the visceral mass by dissection, immersed in household bleach to remove mucilaginous substances and washed in distilled water. Radula length (RL) was measured to the nearest one mm using a ruler. After air-drying, pluricuspid teeth were observed using a binocular microscope, with $80 \times$ final magnification. The external and internal shell surfaces were examined and their characteristics were recorded (Fig. 1). Shell length (SL), shell width (SW), shell width at the apex (SWA), shell height $(\mathrm{SH})$, and shell length from apex to anterior end (SAA) (Fig. 2 for the definition of these measures) were then measured directly to the nearest $0.01 \mathrm{~mm}$ using a digital calliper (Mitutoyo, model CD-15DC).

Identification of the specimens at the species level was based on the morphology of the radula pluricuspid teeth and of the shell (Fig. 1), by comparison with data reported in the literature (Evans 1947, 1953, Fischer-Piette and Gaillard 1959, Christiaens 1973, Fretter and Graham 1994), as previously described (Cabral 2003).

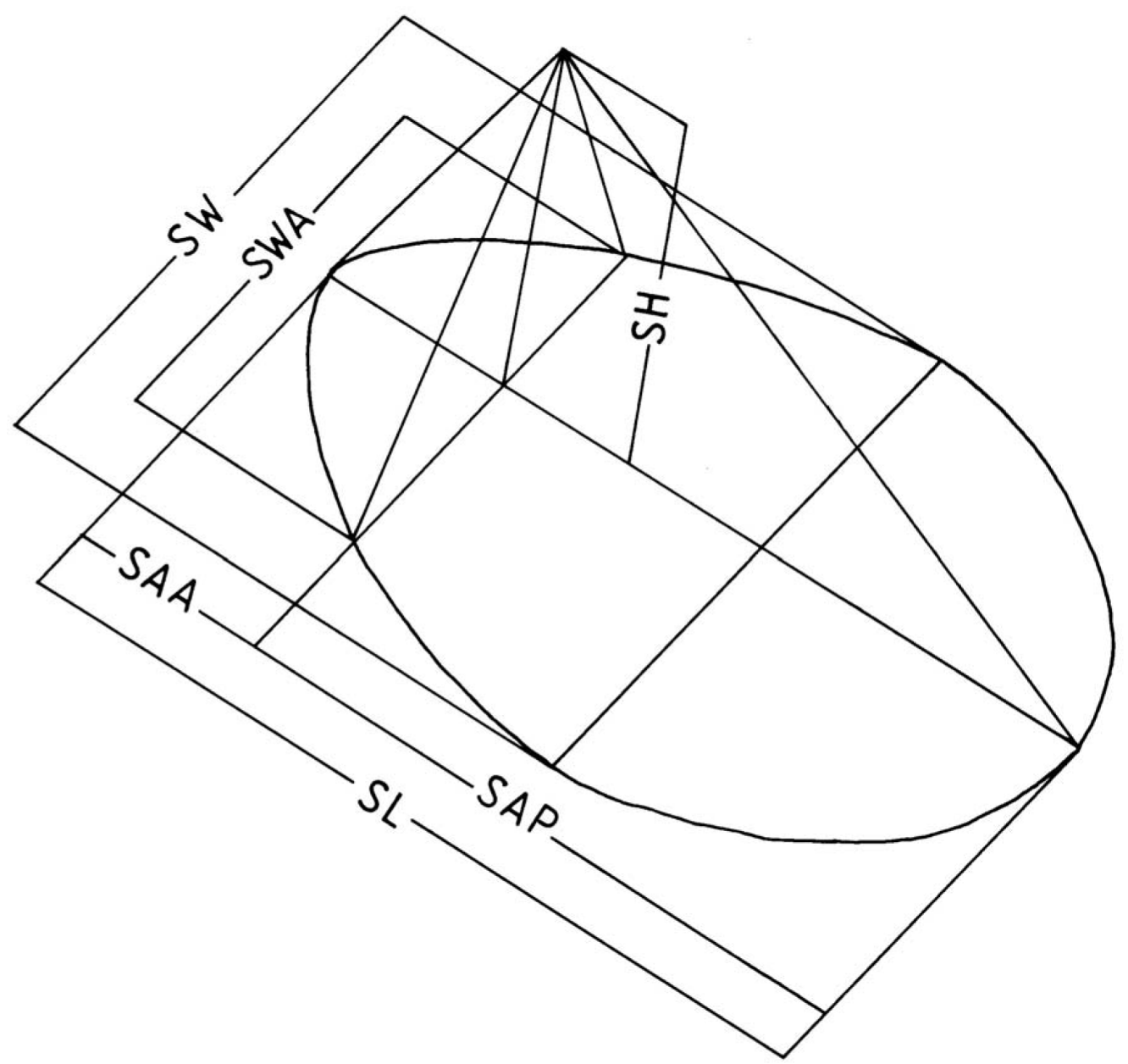

Fig. 2. Distances measured in the shells (description of the variables in the text). 


\section{Shape analysis}

Shell length from apex to posterior end (SAP) was estimated as SL-SAA. Shell base radius (BR) was calculated as $(\mathrm{SL}+\mathrm{SW}) / 4$, shell conicity as the SH/SL ratio, shell cone eccentricity as SAA/SAP, and shell base ellipticity as SW/ SL (Table 1). The base perimeter was calculated as $2 \pi \times$ $\mathrm{BR}$. The base surface area (BS) was calculated as $\pi \times \mathrm{BR}^{2}$. The shell surface area (SS) was determined using the formula of the surface area of a parabolic cone, $3.6 \times \mathrm{BR} \times \sqrt{ }$ $\left(\mathrm{BR}^{2}+((4 / 3) \times \mathrm{SH})\right)$. The total surface area of exposure was calculated as BS + SS. The shell volume was determined using the formula of the volume of a parabolic cone $\left[\left(\pi \times \mathrm{BR}^{2} \times \mathrm{SH}\right) / 2\right]$.

The shape of the limpet shell was decomposed in four parameters: base ellipticity and eccentricity, conicity and cone eccentricity (Table 1). Each one of these parameters was quantified by calculating one or several variables (ratios) (Table 1). Radula relative size was assessed by calculating ratios between radula length and distances measured in the shells. Shape change during growth was assessed by plotting each variable describing shell shape and radula size (ratios variables) against shell length, and by plotting the logarithm of each variable describing shell and radula absolute sizes against the logarithm of shell length. The significance of shell shape change was assessed by testing if the slope of these regressions lines was significantly different from zero (ratio variables) or one (log transformed variables), respectively. All collected specimens were used in shape analysis.

\section{Statistics}

Comparisons of the means of the variables describing shell shape and radula relative size was carried out by ANOVA. The relationship between the variables was assessed by calculating the Pearson linear correlation coefficient. All regressions used the least-squares method. Normality plots of residuals revealed only a few data pairs outside the $95 \%$ envelope range. To test if the slope was significantly different from zero or one, a t test was carried out according to
Zar (1984). Comparisons of the slopes and intercepts of the regressions were carried out by a t test (comparison of two regressions) or by ANCOVA (comparison of three or four regressions), as described by Zar (1984). In the ANCOVA, slopes were compared firstly, and if found to be significantly different, the procedure stopped and regression lines declared significantly different. If slopes were not significantly different, intercepts were then compared. Significance level was set at 0.05 .

\section{Results}

\section{Shell shape and radula relative size}

Shell shape and radula size in the studied Patella species were first evaluated by comparison of the means or medians of the variables used in the analyses of these parameters (Table 2). Similar conclusions were obtained using the mean or median values. Shell base ellipticity was lower than one in all species. It increased from $P$. ulyssiponensis to $P$. rustica and P. intermedia, indicating that these shells have an ellipsoidal/oval/parabolic or ovule-shaped base, narrower in $P$. ulyssiponensis and broader in P. rustica and $P$. intermedia (Fig. 1). Shell base eccentricity was highest in $P$. ulyssiponensis and lowest in $P$. rustica. Shell conicity also increased in this order. $P$. ulyssiponensis and $P$. rustica shells were therefore opposite in shape, from the flat cone with a narrow ovule-shaped base in the former species, to the tall cone with a wide ellipsoidal/oval/parabolic base in the latter species (Fig. 1). Shell cone eccentricity was much far $<1$ in all species. It was lowest in $P$. intermedia and highest in $P$. ulyssiponensis and $P$. rustica, indicating a very asymmetrical cone in the former species, and a more centred apex in the later two species (Fig. 1). Radula relative size increased in the order P. ulyssiponensis, $P$. vulgata, $P$. intermedia, and $P$. rustica. Radula size in $P$. intermedia and $P$. vulgata was similar if expressed as ratios to SL, but different as ratios to $\mathrm{SH}$. For each variable, all means were significantly different according to ANOVA (Table 2).

Table 1. Variables used in the analyses of shell shape.

\begin{tabular}{|c|c|c|}
\hline Shape parameter & Variable & Trends \\
\hline Base ellipticity & SW/SL & $\begin{array}{l}>=1 \quad \text { Circle } \\
<<\quad \text { Ellipse/Oval/Parabola/Ovule } \\
><1, \text { ratio increases with decreasing ellipticity }\end{array}$ \\
\hline Base eccentricity & SWA/SW & $\begin{array}{l}\nabla=1 \quad \text { Circle/Ellipse/Oval/Parabola } \\
<<\quad \text { Ovule } \\
<<1 \text {, ratio increases with transition from ovule to ellipse }\end{array}$ \\
\hline Conicity & $\mathrm{SH} / \mathrm{SL}$ & Increases with increasing conicity \\
\hline Cone eccentricity & SAA/SAP & $\begin{array}{l}\nabla=1 \quad \text { Centred apex/Symmetrical cone } \\
<<1 \quad \text { Apex near the anterior end } \\
><1 \text {, ratio increases with decreasing eccentricity }\end{array}$ \\
\hline
\end{tabular}


Table 2. Descriptive statistics for the variables describing shell shape and radula relative size.

\begin{tabular}{|c|c|c|c|c|c|c|c|c|c|c|c|c|c|c|}
\hline & \multicolumn{3}{|c|}{ P. intermedia } & \multicolumn{3}{|c|}{ P. rustica } & \multicolumn{3}{|c|}{ P. ulyssiponensis } & \multicolumn{3}{|c|}{ P. vulgata } & \multicolumn{2}{|c|}{ ANOVA } \\
\hline & Mean & Median & $\begin{array}{c}\text { CV } \\
\%\end{array}$ & Mean & Median & $\begin{array}{c}\text { CV } \\
\%\end{array}$ & Mean & Median & $\begin{array}{c}\text { CV } \\
\%\end{array}$ & Mean & Median & $\begin{array}{c}\text { CV } \\
\%\end{array}$ & $\mathrm{~F}$ & $\mathrm{p}$ \\
\hline SW/SL & 0.831 & 0.831 & 5.0 & 0.826 & 0.820 & 4.1 & 0.769 & 0.768 & 5.5 & 0.799 & 0.801 & 5.2 & 213 & $<0.00001$ \\
\hline SWA/SW & 0.869 & 0.873 & 5.5 & 0.930 & 0.931 & 2.8 & 0.864 & 0.868 & 5.4 & 0.900 & 0.899 & 7.2 & 82 & $<0.00001$ \\
\hline SH/SL & 0.316 & 0.308 & 23.2 & 0.439 & 0.441 & 12.6 & 0.303 & 0.301 & 14.9 & 0.356 & 0.352 & 16.6 & 174 & $<0.00001$ \\
\hline SAA/SAP & 0.606 & 0.601 & 31.3 & 0.743 & 0.744 & 14.3 & 0.679 & 0.678 & 22.8 & 0.634 & 0.587 & 25.4 & 31 & $<0.00001$ \\
\hline RL/SL & 1.66 & 1.64 & 17.9 & 3.01 & 2.97 & 21.6 & 0.96 & 0.94 & 15.8 & 1.60 & 1.59 & 19.5 & 1364 & $<0.00001$ \\
\hline RL/SH & 5.47 & 5.26 & 25.6 & 6.87 & 6.62 & 20.3 & 3.20 & 3.14 & 18.6 & 4.57 & 4.47 & 20.2 & 485 & $<0.00001$ \\
\hline
\end{tabular}

\section{Shape change during growth}

Shape change during growth was first assessed by plotting each variable describing shell shape and radula size (ratio variables) against shell length (Fig. 3, Table 3). In P. rustica, all variables describing shell shape were not significantly correlated with shell length, indicating that shells of this species maintain a constant shape during growth. In $P$. ulyssiponensis, variables related to base ellipticity and conicity were uncorrelated with shell length. However, variables describing base and cone eccentricity significantly increased with shell size, indicating that shells of this species acquired a more elliptical base and a more centred apex as size increases, but maintained the relative height. In $P$. intermedia and $P$. vulgata, most of the variables describing shell shape were significantly positively correlated with shell length; that is, as shells increased in size, the base became more circular and the cone more centred and relatively taller. In all four Patella species, radula relative size decreased during growth. $P$. intermedia, $P$. ulyssiponensis and $P$. vulgata displayed similar low negative slopes, but $P$. rustica showed a steeper line. Intercepts decreased in the order $P$. rustica, $P$. intermedia, $P$ vulgata and $P$. ulyssiponensis.

During growth, $P$. rustica and $P$. ulyssiponensis shells maintained their opposite morphologies (Fig. 3). P. rustica shells displayed the most circular shell base (higher SW/SL and SWA/SW ratios), and the most conical and centred shells (higher SH/SL and SAA/SAP ratios) of the four species. However, big $P$. intermedia shells had the most circular base and centred apex. On the opposite side, P. ulyssiponensis was the species with narrowest and more ovule-shaped shell base (lowest SW/SL and SWA/SW ratios), and the flattest (lowest SH/SL ratio) shells. P. intermedia and P. vulgata shells displayed intermediate morphologies between these two extremes.

Plotting the variables describing shell and radula sizes against shell length, both log transformed, resulted in highly significant linear correlations (Fig. 4 and 5, Table 4). Regression analysis of the log-log plots confirmed pre-

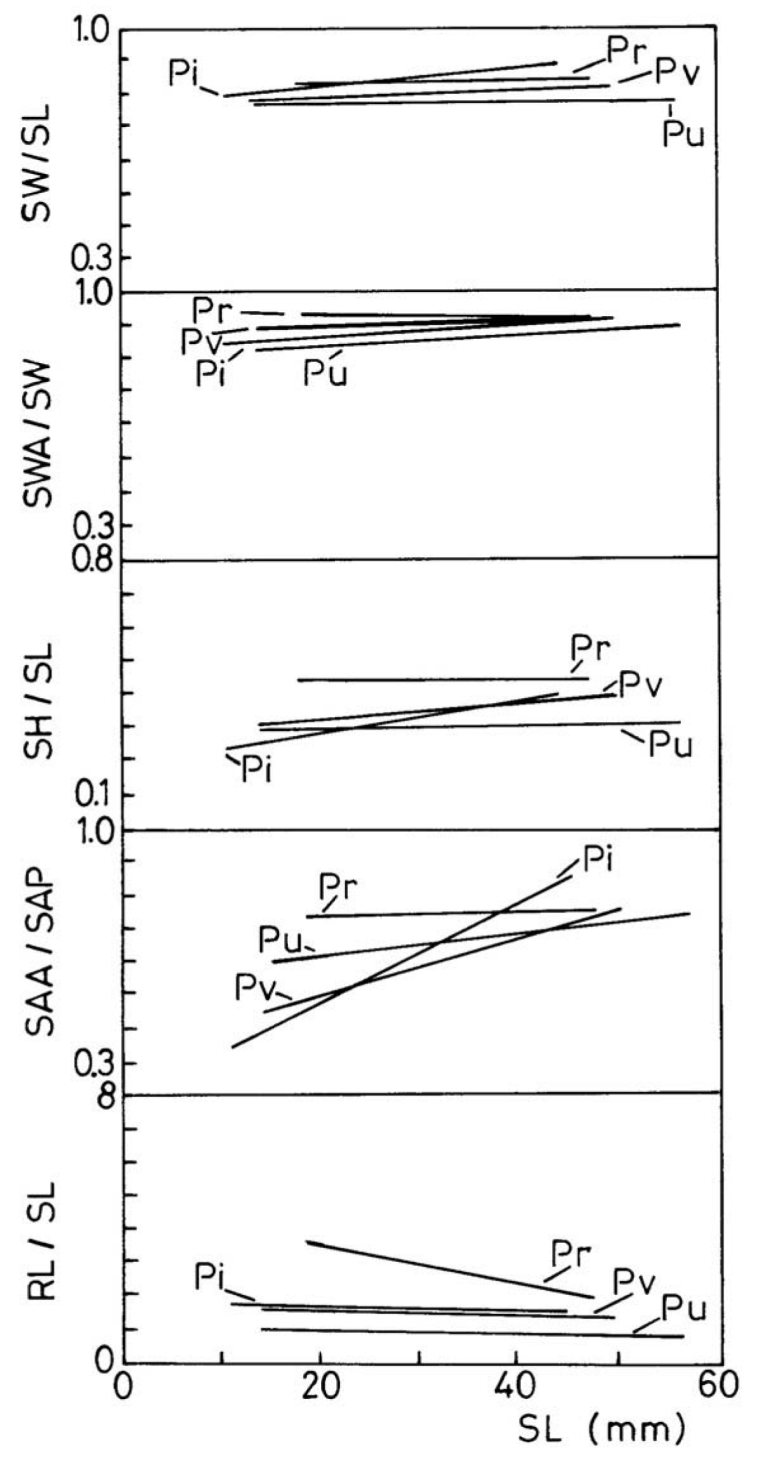

Fig. 3. Plots of ratios describing shell shape or radula relative size changes during growth against shell length. Only the regression lines are displayed $(\mathrm{Pi}=P$. intermedia, $\mathrm{Pr}=P$. rustica, $\mathrm{Pu}=P$. ulyssiponensis, $\mathrm{Pv}=$ P. vulgata). 

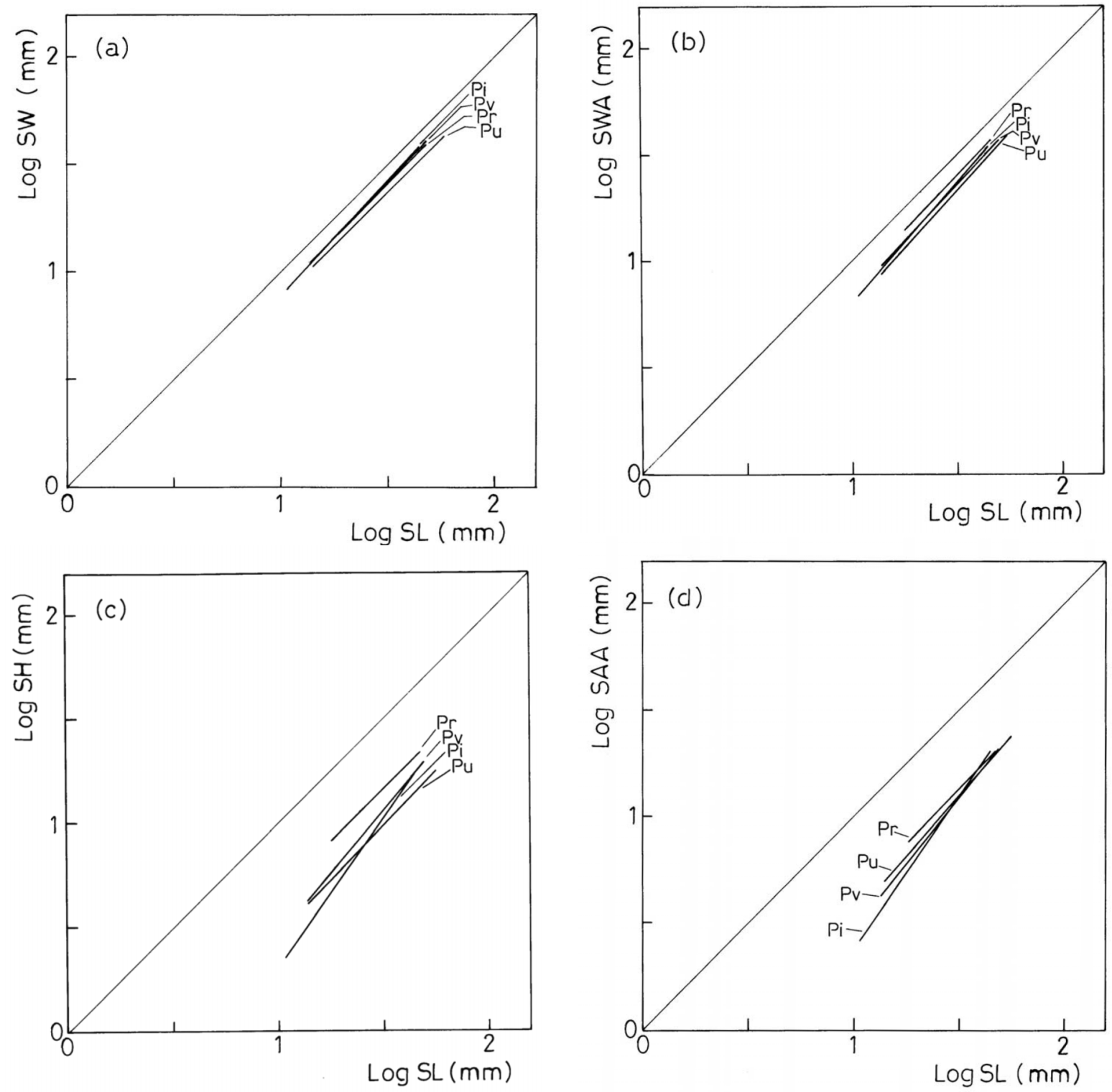

Fig. 4. Plots of the logarithm of shell measures against the logarithm of shell length. (A) Shell width (SW). (B) Shell width at the apex (SWA). (C) Shell height (SH). (D) Shell length from apex to anterior end (SAA) ( $\mathrm{Pi}=$ P. intermedia, $\mathrm{Pr}=$ P. rustica, $\mathrm{Pu}=$ P. ulyssiponensis, $\mathrm{Pv}=$ P. vulgata).

vious analyses using ratio variables. In $P$. rustica, the slopes of all regressions were not significantly different from one, indicating isometric growth, i.e. shell shape was constant as size increased (Huxley 1924, Huxley and Teissier 1936, Gould 1966, Huxley 1993). In P. ulyssiponensis, shell growth was essentially isometric, except for base and cone eccentricity, which increased more than shell length. In $P$. intermedia and P. vulgata, shell growth was positively allometric (Huxley 1924, Huxley and Teissier 1936, Gould 1966, Huxley 1993), the shells being more conical and centred with a less elliptical base as size increased. In the four Patella species, the slope of $\log \mathrm{RL}$ vs $\log \mathrm{SL}$ was $<1$, indicating negative allometry (Huxley 1924, Huxley and Teissier 1936, Gould 1966, Huxley 1993).

The comparison of the regressions of the log-log plots indicated that most slopes and all intercepts were significantly different (Table 5). This suggests different shell and radula shapes and growing patterns among the four studied Patella species, in accordance with results from previous analyses. When the four species were simultaneously compared, the most significantly different slopes were those of regressions describing shell conicity (log SH vs log $\mathrm{SL})$, cone eccentricity (log SAA vs $\log$ SL), and radula relative size (log RL vs $\log \mathrm{SL})$; the least significantly different 
Table 3. Parameters of the regression lines (ratios) for evaluating shape change during growth.

\begin{tabular}{|c|c|c|c|c|c|c|c|}
\hline \multirow[b]{2}{*}{ Species } & \multirow{2}{*}{$\begin{array}{c}\text { Variable } \\
\text { vs SL }\end{array}$} & \multirow{2}{*}{$\begin{array}{c}\text { Pearson } \\
\mathrm{r}\end{array}$} & \multirow[b]{2}{*}{ Intercept } & \multicolumn{4}{|c|}{ Slope } \\
\hline & & & & Value & $95 \%$ Con & ce limits & p slope $\neq 0$ \\
\hline \multirow[t]{5}{*}{ P. intermedia } & SW/SL & 0.269 & 0.778 & 0.0019 & 0.0014 & 0.0024 & $<0.001$ \\
\hline & SWA/SW & 0.246 & 0.814 & 0.0020 & 0.0014 & 0.0025 & $<0.001$ \\
\hline & SH/SL & 0.380 & 0.185 & 0.0047 & 0.0039 & 0.0055 & $<0.001$ \\
\hline & SAA/SAP & 0.469 & 0.188 & 0.0150 & 0.0130 & 0.0171 & $<0.001$ \\
\hline & RL/SL & -0.136 & 1.85 & -0.0007 & -0.0003 & -0.0010 & $<0.001$ \\
\hline \multirow[t]{5}{*}{ P. rustica } & SW/SL & 0.103 & 0.808 & 0.00062 & -0.0005 & 0.0018 & $>0.20$ \\
\hline & SWA/SW & 0.0184 & 0.928 & 0.000086 & -0.00078 & 0.00096 & $>0.50$ \\
\hline & SH/SL & -0.0202 & 0.445 & -0.00020 & -0.0021 & 0.0017 & $>0.50$ \\
\hline & SAA/SAP & 0.043 & 0.719 & 0.00082 & -0.0028 & 0.0044 & $>0.50$ \\
\hline & RL/SL & -0.515 & 4.74 & -0.0060 & -0.0078 & -0.0041 & $<0.001$ \\
\hline \multirow[t]{5}{*}{ P. ulyssiponensis } & SW/SL & 0.053 & 0.755 & 0.00036 & -0.0003 & 0.0010 & $>0.20$ \\
\hline & SWA/SW & 0.220 & 0.803 & 0.0017 & 0.00095 & 0.0024 & $<0.001$ \\
\hline & SH/SL & 0.051 & 0.289 & 0.00037 & -0.00033 & 0.0011 & $>0.20$ \\
\hline & SAA/SAP & 0.137 & 0.553 & 0.0034 & 0.0010 & 0.0058 & $<0.01$ \\
\hline & RL/SL & -0.189 & 1.13 & -0.00046 & -0.00023 & -0.00069 & $<0.001$ \\
\hline \multirow{5}{*}{ P. vulgata } & SW/SL & 0.182 & 0.762 & 0.0011 & 0.0005 & 0.0017 & $<0.005$ \\
\hline & SWA/SW & 0.105 & 0.867 & 0.0010 & 0.00004 & 0.0019 & $0.02-0.05$ \\
\hline & SH/SL & 0.276 & 0.276 & 0.0024 & 0.0015 & 0.0032 & $<0.001$ \\
\hline & SAA/SAP & 0.373 & 0.339 & 0.0087 & 0.0065 & 0.0108 & $<0.001$ \\
\hline & RL/SL & -0.150 & 1.83 & -0.00068 & -0.00023 & -0.0011 & $<0.005$ \\
\hline
\end{tabular}

slopes were those of the regressions related to base ellipticity and eccentricity. The most differentiating morphological traits among the four studied limpet species were the shell cone height and centring and radula relative size.

Plots of the ratios shell base perimeter/shell volume, shell surface area/shell volume and total surface area/shell

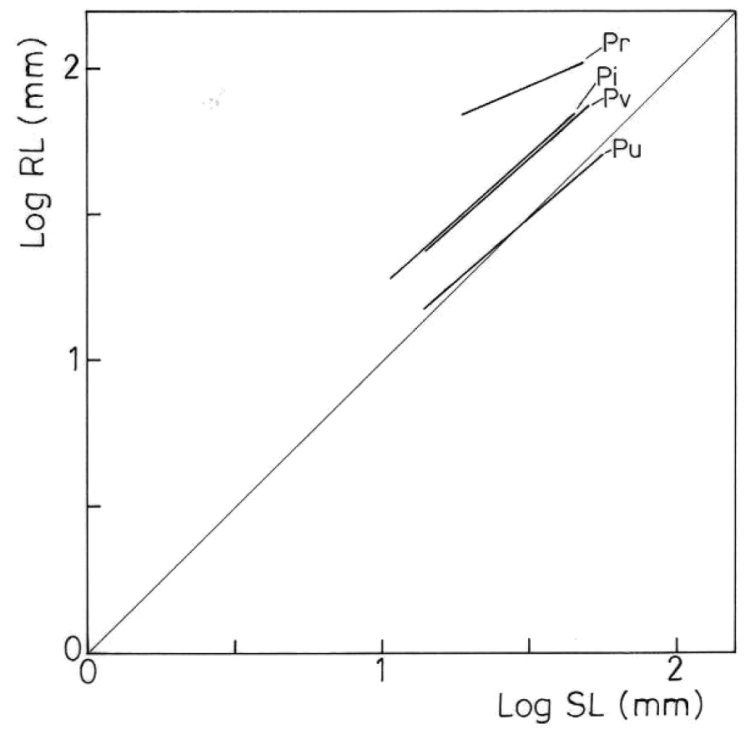

Fig. 5. Plots of the logarithm of radula length against the logarithm of shell length $(\mathrm{Pi}=P$. intermedia, $\mathrm{Pr}=P$. rustica, $\mathrm{Pu}=P$. ulyssiponensis, $\mathrm{Pv}=$ P. vulgata). volume, against shell length, are shown in Fig. 6 to 8. For all four species, increasing shell length corresponded to decreasing ratios. Except for small shells, P. rustica and $P$. ulyssiponensis displayed the lowest and highest ratios at a given shell length, respectively, in accordance with the highest and lowest mean conicities, respectively, exhibited by these two species. $P$. intermedia and $P$. vulgata shells exhibited intermediate features. P. ulyssiponensis shells exhibited the lowest slope, in accordance with the isometric increase in height with length. $P$. intermedia and $P$. vulgata shells exhibited the highest slopes due to the allometric increase in shell height with shell length.

\section{Discussion}

The shells of $P$. intermedia, P. rustica, $P$. ulyssiponensis and $P$. vulgata exhibited characteristic shapes and growing patterns. However, whereas P. rustica and $P$. ulyssiponensis shells exhibited opposite morphological traits, $P$. intermedia and P. vulgata shells shared some characteristics. $P$. rustica shells were tall and centred cones, with almost circular base. Shell shape was maintained during growth. On the contrary, $P$. ulyssiponensis shells were flat cones, with an ovule-shaped base. Shell shape was basically constant during growth, except that shells became more centred as size increased. P. intermedia and P. vulgata shells displayed intermediate shell shapes between these two extremes morphologies, but both displayed pronounced 
Table 4. Parameters of the regression lines (log transformed) for evaluating shape change during growth and testing isometric vs allometric growth.

\begin{tabular}{|c|c|c|c|c|c|c|c|c|}
\hline \multirow[b]{2}{*}{ Species } & \multirow{2}{*}{$\begin{array}{l}\text { Variable vs } \\
\text { Log SL }\end{array}$} & \multirow{2}{*}{$\begin{array}{c}\text { Pearson } \\
\mathrm{r}\end{array}$} & \multirow[b]{2}{*}{ Intercept } & \multicolumn{3}{|c|}{ Slope } & \multirow[b]{2}{*}{ p slope $\neq 1$} & \multirow{2}{*}{$\begin{array}{l}\text { Isomery vs } \\
\text { Allometry } \\
\text { at } 0.05 \text { leve }\end{array}$} \\
\hline & & & & Value & $95 \% \mathrm{C}$ & ice limits & & \\
\hline \multirow{5}{*}{ P. intermedia } & Log SW & 0.981 & -0.173 & 1.064 & 1.049 & 1.080 & $<0.001$ & Allometry \\
\hline & Log SWA & 0.971 & -0.323 & 1.126 & 1.106 & 1.146 & $<0.001$ & Allometry \\
\hline & $\log \mathrm{SH}$ & 0.853 & -1.115 & 1.421 & 1.358 & 1.484 & $<0.001$ & Allometry \\
\hline & Log SAA & 0.906 & -1.063 & 1.436 & 1.387 & 1.485 & $<0.001$ & Allometry \\
\hline & $\log R L$ & 0.753 & 0.349 & 0.906 & 0.848 & 0.963 & $<0.001$ & Allometry \\
\hline \multirow[t]{5}{*}{ P. rustica } & Log SW & 0.980 & -0.122 & 1.026 & 0.987 & 1.065 & $0.20-0.50$ & Isometry \\
\hline & Log SWA & 0.973 & -0.164 & 1.033 & 0.987 & 1.080 & $0.10-0.20$ & Isometry \\
\hline & $\log \mathrm{SH}$ & 0.833 & -0.371 & 1.007 & 0.882 & 1.133 & $>0.50$ & Isometry \\
\hline & Log SAA & 0.918 & -0.421 & 1.032 & 0.948 & 1.116 & $0.20-0.50$ & Isometry \\
\hline & $\log R L$ & 0.395 & 1.289 & 0.435 & 0.245 & 0.626 & $<0.001$ & Allometry \\
\hline \multirow[t]{5}{*}{ P. ulyssiponensis } & Log SW & 0.958 & -0.149 & 1.022 & 0.992 & 1.051 & $0.10-0.20$ & Isometry \\
\hline & Log SWA & 0.955 & -0.318 & 1.089 & 1.056 & 1.122 & $<0.001$ & Allometry \\
\hline & $\log \mathrm{SH}$ & 0.786 & -0.615 & 1.059 & 0.978 & 1.139 & $>0.50$ & Isometry \\
\hline & Log SAA & 0.865 & -0.608 & 1.133 & 1.070 & 1.197 & $0.02-0.05$ & Allometry \\
\hline & $\log R L$ & 0.710 & 0.173 & 0.872 & 0.790 & 0.950 & $<0.005$ & Allometry \\
\hline \multirow[t]{5}{*}{ P. vulgata } & Log SW & 0.970 & -0.163 & 1.042 & 1.016 & 1.068 & $<0.001$ & Allometry \\
\hline & Log SWA & 0.974 & -0.264 & 1.078 & 1.053 & 1.103 & $<0.001$ & Allometry \\
\hline & $\log \mathrm{SH}$ & 0.869 & -0.782 & 1.216 & 1.146 & 1.285 & $<0.001$ & Allometry \\
\hline & Log SAA & 0.894 & -0.821 & 1.261 & 1.198 & 1.325 & $<0.001$ & Allometry \\
\hline & $\log R L$ & 0.719 & 0.329 & 0.873 & 0.792 & 0.955 & $<0.001$ & Allometry \\
\hline
\end{tabular}

shell shape changes during growth. Small $P$. intermedia shells were flat, with a very anterior apex, but as size increased they became more conical and centred. P. vulgata shells displayed similar but less marked shell growing trends. In the current identification schemes for the European Atlantic Patella species, the most used characteristics of the shell are the texture and pigmentation of the internal and external surfaces. The results reported in the present work indicated that shell shape, mainly conicity and cone eccentricity, should be taken into account in the identification of specimens.

Limpets are one of the most abundant groups of molluscs in the intertidal rocks of sea-shores. At high tide, waves crash on the shore and impose intense hydrodynamic forces (Denny and Blanchette 2000). Organisms living on the surf zone are subjected to water flow of very high velocity and acceleration. In this environment, molluscs face the problem of being swept away (Vermeij 1993). It has been estimated that the lowest risk of dislodgment for a limpet is associated with a centred apex, and a SH/SL or SH/SW ratio of ca 0.53 (Denny 2000, Denny and Blanchette 2000). Displacement of the apex away from the centre of the shell, and/or lower or higher SH/SL ratios should result in increasing tensile stress and concomitant higher probability of being swept away (Denny 1988, 2000, Denny and Blanchette 2000). However, limpets overall the world do not conform to these patterns. Vermeij (1973) studied shell shape in several species collected in different sites of Latin America, the West Indies, West Afri$\mathrm{ca}$, and the Middle East. Conicity was evaluated by the $\mathrm{SH}$

Table 5. Comparison of the regression lines for evaluating shape change during growth in the studied Patella species.

\begin{tabular}{lcccc}
\hline Variable vs & \multicolumn{2}{c}{ Comparison of slopes } & \multicolumn{2}{c}{ Comparison of intercepts } \\
Log SL & F/t & p & F/t & Not tested \\
\hline Log SW & 3.20 & $0.05-0.02$ & 168.1 & - \\
Log SWA & 1.17 & $>0.50$ & Not tested & - \\
Log SH & 20.4 & $<0.001$ & Not tested & - \\
Log SAA & 18.5 & $<0.001$ & Not tested & - \\
Log RL & 8.85 & $<0.001$ & & - \\
\hline
\end{tabular}




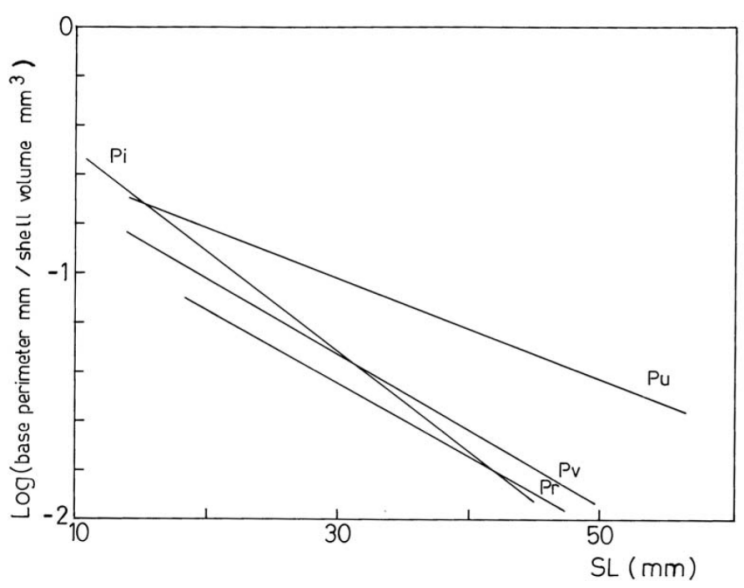

Fig. 6. Plots of the ratio between the base perimeter and shell volume, against shell length $(\mathrm{Pi}=P$. intermedia, $\mathrm{Pr}=$ P. rustica, $\mathrm{Pu}$ $=$ P. ulyssiponensis, $\mathrm{Pv}=$ P. vulgata .

/ $\sqrt{ }(\mathrm{SL} \times \mathrm{SW})$ ratio, which is ca the mean of SH/SL and $\mathrm{SH} / \mathrm{SW}$ ratios. Mean conicity for the studied Acmaea, Cellana, Patella and Scurria species (ten, three, three and one species) was very uniform, and ranged between 0.334 and 0.386 . Denny (1989) presented shell ratio measurements for 14 limpet species from South Africa and the west coast of North America. Mean SAA/SL and SH/SL ratios for these species were in the $0.190-0.500$ and $0.185-0.665$ ranges, respectively. Denny (2000) compiled data for 79 species of 12 genera of limpets from all over the world, mostly outside Europe. Overall mean SAA/SL, SH/SL and $\mathrm{SH} / \mathrm{SW}$ ratios for these species were $0.35,0.34$ and 0.42 , respectively. Branch and Marsh (1978) studied shell shape in six Patella species from the South Africa coast. Mean SAA/SAP and SH/SL ratios ranged between 0.64-0.81 and $0.22-0.43$. In the present work, mean SAA/SL, SH/ SL and SH/SW ratios for P. intermedia, P. rustica, P. ulys-

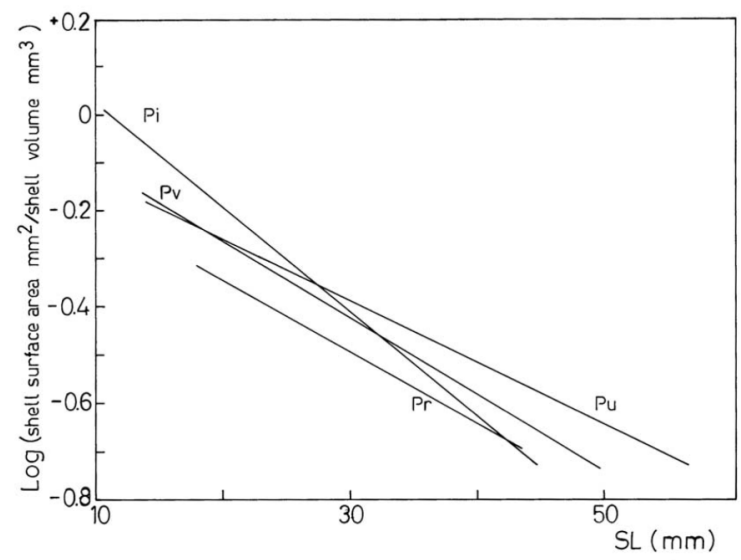

Fig. 7. Plots of the ratio between shell surface area and shell volume, against shell length $(\mathrm{Pi}=P$. intermedia, $\mathrm{Pr}=P$. rustica, $\mathrm{Pu}=P$. ulyssiponensis, $\mathrm{Pv}=$ P. vulgata).

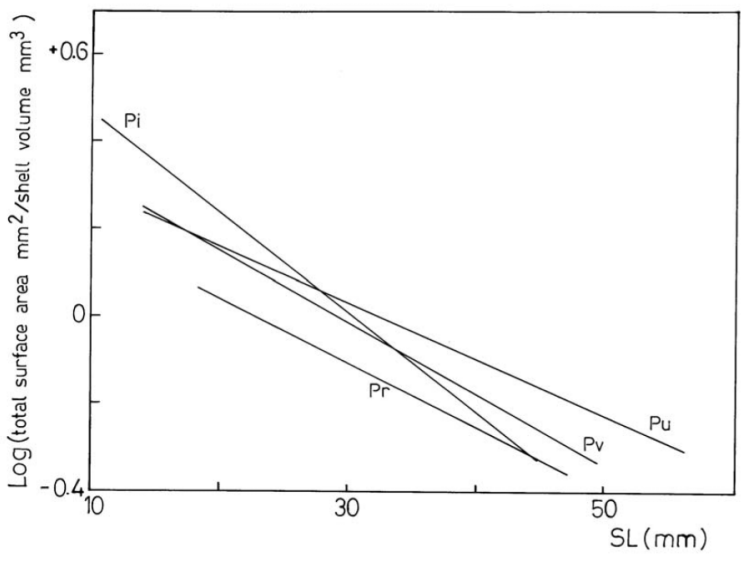

Fig. 8. Plots of the ratio between total surface area and shell volume, against shell length $(\mathrm{Pi}=$ P. intermedia, $\mathrm{Pr}=P$. rustica, $\mathrm{Pu}=P$. ulyssiponensis, $\mathrm{Pv}=$ P. vulgata).

siponensis and P. vulgata were $0.370-0.424,0.303-0.439$, and $0.380-0.532$, respectively (Table 2 ), indicating that European Atlantic limpets also display an under theoretical optimum shell shape in relation to dislodgment by wave action.

An explanation for the observed difference between the theoretical optimum shell shape and the observed limpet shapes is that tenacity is very important, or even dominant, in the resistance of the limpets to being swept away in the seashore environment. Indeed, limpets are known to exhibit huge strengths of adhesion to the substratum. Branch and Marsh (1978) compared tenacity in six Patella species from the South Africa coast. Tenacity increased in the order P. oculus, P. granatina, P. granularis, P. longicosta, $P$. argenvillei, and $P$. cochlear, corresponding to increasing exposure to wave action in the shore.

Limpets are subjected to wetting and drying each tidal cycle (Branch 1981). Ability to resist desiccation is therefore of primary importance for intertidal limpets, since the loss of body water can be the direct cause of death due to desiccation (Hyman 1967, Davies 1969). Moreover, limpets are probably more prone to heating than other organisms, since a large surface area is exposed to sun and little shadow is cast (Branch 1975). When immersed, limpets rapidly equilibrate with seawater temperature, but when exposed to sunlight and air temperatures, the temperature of the soft body can exceed the atmospheric temperatures (Davies 1970, Branch 1981). The primary site of evaporation from a limpet's body is at the shell periphery (Davies 1969, Vermeij 1973, Denny 2000). Over the course of a sunny low tide, limpets firmly attached to the home scar lose less water than limpets out of the home scar or than limpets allowed to elevate shell margins (Garrity 1984). With direct sunlight, the amount of heat energy absorbed depends on the surface area of the shell perpendicular to the sun's rays (Vermeij 1973, 1993). Heat loss, however, 
depends on the total surface area, including surfaces that are not at right angles to the incoming rays, and cooling by the loss of water from the foot and from the space between the foot and the shell (Vermeij 1973, 1993). Desiccation and temperature of the animal body are therefore directly dependent on the perimeter of the base (and the strength of attachment to the home scar), the surface area of exposure and the mass of the soft body. Since limpets have fundamentally a conic shell, and the soft body size and the reservoir of water are determined by the shell volume, with increasing shell size, the ratios perimeter or surface area/ soft body mass decrease, resulting in lower desiccation and soft body temperature (Hyman 1967, Davies 1969, 1970, Branch 1975, 1981, Vermeij 1973, 1993, Fretter and Graham 1994). These facts have been experimentally confirmed (Vermeij 1973, Branch 1975, Garrity 1984).

In the present study of European Atlantic limpets, shell conicity increased in the order, P. ulyssiponensis, P. intermedia, P. vulgata, and P. rustica (Table 2). This order corresponded to an increasingly higher level in the shore, suggesting that shell shape in European Atlantic limpets can be directly related to resistance to desiccation and high temperature stresses, as reported for other limpet species. This hypothesis was confirmed by plotting the ratios in Fig. 6 to 8. All these results favour the interpretation that shell shape in European Atlantic limpets can be related, at least partially, to the avoidance of desiccation and heat stresses. Except for small shells, P. ulyssiponensis shells were the flattest, and therefore, the most prone to water loss and heating this species is out of water only at low tide. P. rusti$c a$ shells were the tallest, and except for very big shells, the least prone to lose water and heat this species is out of water for most of the day. The high slope exhibited by $P$. intermedia and $P$. vulgata suggested that as the animal increases in size it is less prone to desiccation and heating stresses. However, some characteristics of the shells of these species might also influence the amplitude of desiccation and heating. P. ulyssiponensis shells are usually covered by algae, and this can further decrease heating. On the contrary, $P$. rustica shells are dark coloured, and this can antagonize the advantage of pronounced shell conicity exhibited by this species (Vermeij 1971).

The radula of the studied Patella species displayed negative allometric growth. Branch (1975) reported growth functions for seven Patella species of the South Africa coasts. Whilst in four species the slope of the log shell height vs log shell length plot was $\approx 1$, indicating isometric growth in height, it was $>1.3$ in three other species, indicating allometric growth. However, no statistical tests were reported for these data. The length of the radula in European Atlantic limpets increased in the order $P$. ulyssiponensis, P. vulgata, P. intermedia, and $P$. rustica, corresponding to an increasing water level in the shore. Limpets are grazers, and feed on algae and detritus found on the substratum. The overall abundance of algae in the intertidal zone shows a general decreasing trend from the lowest to the highest levels of the shore, since most species do not tolerate drying for long periods. According to Fretter and Graham (1994), the length of the radula increase with increasing usage and wear. The results presented here are compatible with this view, and suggested that the very long radula of $P$. rustica can be related to the low density of algae in the higher shore levels, with concomitant higher usage of the radula in order to scratch the amount of food necessary for survival.

\section{References}

Branch, G. M. 1975. Ecology of Patella species from the Cape Peninsula, South Africa. IV. Desiccation. - Mar. Biol. 32: 179-188.

Branch, G. M. 1981. The biology of limpets: physical factors, energy flow, and ecological interactions. - Ann. Rev. Oceanogr. Mar. Biol. 19: 235-379.

Branch, G. M. and Marsh, A. C. 1978. Tenacity and shell shape in six Patella species: adaptative features. - J. Exp. Mar. Biol. Ecol. 34: 111-130.

Cabral, J. P. 2003. Characterization and multivariate analysis of Patella intermedia, Patella ulyssiponensis and Patella vulgata from Póvoa de Varzim (Northwest Portugal). - Iberus 21: 117.

Christiaens, J. 1973. Révision du genre Patella (Mollusca, Gastropoda). - Bull. Museum d'Hist. Nat., 3 série, Zool. 121: 1305-1392.

Davies, S. P. 1969. Physiological ecology of Patella. III. Desiccation effects. - J. Mar. Biol. Assoc. UK 49: 291-304.

Davies, P. S. 1970. Physiological ecology of Patella. IV. Environmental and limpet body temperatures. - J. Mar. Biol. Assoc. UK 50: 1069-1077.

Denny, M. W. 1988. Biology and the mechanics of the waveswept environment. - Princeton University Press.

Denny, M. W. 1989. A limpet shell shape that reduces drag: laboratory demonstration of a hydrodynamic mechanism and an exploration of its effectiveness in nature. - Can. J. Zool. 67: 2098-2106.

Denny, M. W. 2000. Limits to optimization: fluid dynamics, adhesive strength and the evolution of shape in limpet shells. J. Exp. Biol. 203: 2603-2622.

Denny, M. W. and Blanchette, C. A. 2000. Hydrodynamics, shell shape, behaviour and survivorship in the owl limpet Lottia gigantea. - J. Exp. Biol. 203: 2623-2639.

Ellem, G. K. et al. 2002. Shell clamping behaviour in the limpet Cellana tramoserica. - J. Exp. Biol. 205: 539-547.

Evans, R. G. 1947. Studies in the biology of British limpets. I. The genus Patella in Cardigan Bay. - Proc. Zool. Soc. London 117: 411-423.

Evans, R. G. 1953. Studies in the biology of British limpets - the genus Patella on the south coast of England. - Proc. Zool. Soc. London 12: 357-376.

Evans, R. G. 1957. The intertidal ecology of some localities on the Atlantic coast of France. - J. Ecol. 45: 245-271.

Fisher-Piette, E. and Gaillard, J. M. 1959. Les Patelles, au long des cotes atlantiques ibériques et nord-marocaines. - J. Conchyliol. 99: 135-200.

Fretter, V. and Graham, A. 1994. British prosobranch molluscs. Their functional anatomy and ecology. - The Ray Society. 
Garrity, S. D. 1984. Some adaptations of gastropods to physical stress on a tropical rocky shore. - Ecology 65: 559-574.

Gould, S. J. 1966. Allometry and size in ontogeny and phylogeny. - Biol. Rev. 41: 587-640.

Guerra, M. T. and Gaudencio, M. J. 1986. Aspects of the ecology of Patella spp. On the Portuguese coast. Hidrobiología 142: 57-69.

Huxley, J. S. 1924. Constant differential growth-ratios and their significance. - Nature 114: 895-896.

Huxley, J. S. 1993. Problems of relative growth. - The Johns Hopkins University Press.

Huxley, J. S. and Teissier, G. 1936. Terminology of relative growth. - Nature 137: 780-781.

Hyman, L. H. 1967. The invertebrates. Volume VI. Mollusca I. - McGraw-Hill.

Ibañez, M. 1982. Sistemática y ecología del género Patella en la Costa Vasca I. - Lurralde 5: 69-78.
Smith, A. M. et al. 1999. Differences in the composition of adhesive and non-adhesive mucus from the limpet Lottia limatula. - Biol. Bull. 196: 34-44.

Vermeij, G. J. 1971. Temperature relationships of some tropical Pacific intertidal gastropods. - Mar. Biol. 10: 308-314.

Vermeij, G. J. 1973. Morphological patterns in high-intertidal gastropods: adaptive strategies and their limitations. - Mar. Biol. 20: 319-346.

Vermeij, G. J. 1993. A natural history of shells. - Princeton University Press.

Williams, G. A. et al. 1999. Foraging in the limpet Patella vulgata: the influence of rock slope on the timing of activity. - J. Mar. Biol. Assoc. UK 79: 881-889.

Zar, J. H. 1984. Biostatistical analysis. - Prentice-Hall. 